\title{
The impact of rotavirus vaccination on emergency department visits and hospital admissions for acute diarrhea in children under 5 years
}

Rodrigo locatelli Pedro Paulo ${ }^{1 *}$, André Broggin Dutra Rodrigues², Beatriz Marcondes Machado ${ }^{3}$, Alfredo Elias Gillo ${ }^{3}$

${ }^{1}$ MSC in Pediatrics, Hospital Universitário, Universidade de São Paulo (HU-USP), São Paulo, SP, Brazil

${ }^{2} \mathrm{MSc}$ in Pediatrics, São Paulo, SP, Brazil

${ }^{3} \mathrm{PhD}$ in Pediatrics, HU-USP, São Paulo, SP, Brazil

Study conducted at Hospital Universitário, Universidade de São Paulo (HU-USP), São Paulo, SP, Brazil

Article received: $6 / 29 / 2016$ Accepted for publication: $7 / 26 / 2016$

*Correspondence: Hospital Universitário da USP Departamento de Clínica Pediátrica Address: Av. Prof. Lineu Prestes, 2565 São Paulo, SP - Brazil Postal code: 05508-000 locateli@terra.com.br

http://dx.doi.org/10.1590/1806-9282.62.06.506

\section{SUMmARY}

Introduction: Acute diarrheal disease is the second cause of death in children under 5 years. In Brazil, from 2003 to 2009, acute diarrhea was responsible for nearly 100,000 hospital admissions per year and $4 \%$ of the deaths in children under 5 years. Rotavirus is the leading cause of severe acute diarrhea worldwide. In 2006, the rotavirus monovalent vaccine (RV1) was added to the Brazilian National Immunization Program.

Objectives: To analyze the impact of the RV1 on emergency department (ED) visits and hospital admissions for acute diarrhea.

Method: A retrospective ecologic study at the University Hospital, University of São Paulo. The study analyzed the pre-vaccine (2003-2005) and the post-vaccine (2007-2009) periods. We screened the main diagnosis of all ED attendances and hospital admissions of children under 5 years in an electronic registry system database and calculated the rates of ED visits and hospital admissions. The reduction rate was analyzed according to the following formula: reduction $(\%)=(1$ odds ratio $) \times 100$.

Results: The rates of ED visits for acute diarrhea was 85.8 and 80.9 per 1,000 total ED visits in the pre and post vaccination periods, respectively, resulting in $6 \%$ reduction (95CI 4 to $9 \%, \mathrm{p}<0.001$ ). The rates of hospital admissions for acute diarrhea was 40.8 per 1,000 in the pre-vaccine period and dropped to 24.9 per 1,000 hospitalizations, resulting in $40 \%$ reduction (95CI 22 to $54 \%, \mathrm{p}<0.001$ ).

Conclusion: The introduction of the RV1 vaccine resulted in $6 \%$ reduction in the ED visits and $40 \%$ reduction in hospital admissions for acute diarrhea.

Keywords: diarrhea, rotavirus, vaccines, emergency medical services, hospitalization, epidemiology, preschooler.

\section{INTRODUCTION}

According to data from the World Health Organization (WHO), acute diarrheal disease is the second most common cause of death in children under 5 years of age, accounting for $10 \%$ of deaths among children in this age group. Furthermore, each year there are around 1.7 billion cases of diarrheal disease, leading to the death of 760,000 children aged under $5 .{ }^{1,2}$ The WHO recommends the use of vaccines against rotavirus as an essential measure in the prevention of the disease.

According to data from the Ministry of Health, in Brazil, between 2003 and 2009, there were around 80,000 to 120,000 hospital admissions per year due to acute diarrheal disease in children under 5 years of age. ${ }^{3}$ In 2006, 2,236 children died (around $4 \%$ of the deaths). Between 2003 and 2009 in the state of São Paulo there were approximately 7,000 to 11,000 hospital admissions due to acute diarrheal disease in children under 5 years of age. In 2006, 135 children died (around $1.5 \%$ of the deaths). ${ }^{3}$

Rotavirus is the main causative agent of severe diarrhea throughout the world. In 2004, it was responsible for $29 \%$ of all deaths caused by diarrhea in children less than 5 years of age worldwide. As such, it was responsible for approximately 527,000 deaths that year in children under 5 
years of age. ${ }^{4}$ In developing countries, it is estimated that rotavirus is responsible for approximately $40 \%$ of all hospital admissions due to acute diarrhea. ${ }^{5}$ From 2005 to 2006, the prevalence of rotavirus in hospital admissions for acute diarrhea and dehydration in children under age 5 in Brazil was $43.3 \% .{ }^{6}$ With relation to consultations at the emergency room, rotavirus is responsible for 11.9 to $20.8 \%$ of visits due to acute diarrhea. ${ }^{7-9}$ In the city of São Paulo, rotavirus infections present a seasonal distribution, with a predominance of cases in the months of May and June. ${ }^{6}$

The vaccine used in the National Immunization Program (NIP) is a monovalent, live, attenuated virus vaccine, delivered orally, which contains a strain of human rotavirus (serotype G1P1A [8]), called RIX 4414. This vaccine was introduced in the NIP in March 2006. In the prelicensing studies this vaccine proved to be safe and effective, especially for the prevention of severe cases. ${ }^{10}$

After the introduction of the vaccine in Brazil, two studies used the National Health Information System (Datasus) and showed there was a $21 \%$ reduction in hospital admissions due to acute diarrhea in the Southeast,${ }^{11}$ and a reduction of $40 \%$ in the state of São Paulo. ${ }^{12}$ Another study at a private hospital in the city of São Paulo showed a 59\% reduction in hospital admissions due to acute diarrhea caused by rotavirus in children less than 5 years of age. ${ }^{13}$ However, there are still no studies evaluating the impact of the rotavirus vaccine at public hospitals in the city of São Paulo.

\section{Objectives}

- To verify the impact of the monovalent vaccine against rotavirus in consultations due to acute diarrheal disease in children less than 5 years of age at the emergency room of the University of São Paulo's University Hospital.

- To verify the impact of the monovalent vaccine against rotavirus in hospital admissions due to acute diarrheal disease in children less than 5 years of age at the emergency room of the University of São Paulo's University Hospital.

- To verify the impact of the monovalent vaccine against rotavirus in the consultations and hospital admissions caused by acute diarrheal disease at the peak incidence of rotavirus infections (the months of May and June).

\section{Method}

A retrospective ecological study was conducted during the period from January 1, 2003 to December 31, 2009. The period was divided into three for organization and analysis of the data: the pre-vaccine period (2003 to 2005), the transition period (2006) and the post-vaccine period (2007 to 2009). The months of May and June were considered as the months of peak incidence of rotavirus infection.

The study was conducted at the University of São Paulo's University Hospital (HU-USP), which is a secondarylevel teaching hospital. The main diagnoses of the emergency room care are encoded by the medical file service (SAME) using the tenth revision of the International Statistical Classification of Diseases and Related Health Problems (ICD-10). The data is transferred to a database by the hospital's data processing center (DPC). The hospital admission diagnosis is coded by the SAME using the ICD-10, and the discharge summary is stored via electronic medical record. All of the data is transferred to a database by the hospital's DPC.

At the HU-USP the diagnosis of acute diarrhea is in accordance with the WHO's definition and is characterized by three or more episodes of liquid or semi-liquid evacuations in a 24 hour period, the duration of which does not exceed 14 days. In breastfeeding infants without formed stools, the mother's reports in relation to increased frequency of bowel movements or change in the characteristics of stools should be considered for the diagnosis. The HU-USP medical file service uses the code A.09 (ICD-10) for the diagnosis of acute diarrheal disease.

The study included all children under the age of 5 that underwent a consultation at the HU-USP emergency room in the study period. We excluded children who were transferred from another hospital for admission.

The following data were obtained with respect to consultations in the emergency room: name, appointment number, age, sex, visit date, and diagnosis (coded using ICD-10).

Regarding hospital admissions for acute diarrhea, all of the discharge summaries of patients older than 28 days and under 5 years of age were selected. The following data were obtained: name, appointment number, age, sex, date of admission, date of discharge, and diagnosis (coded using ICD-10).

The variables analyzed were: number of consultations due to acute diarrhea at the emergency room; number of hospital admissions for acute diarrhea; consultation rate for acute diarrhea at the emergency room per 1,000 general emergency room consultations in the period; and the hospital admission rate due to acute diarrhea per 1,000 general admissions in the period. The main exposure factor is rotavirus vaccination (RV1), therefore, vaccination coverage against rotavirus in children under 5 years of age in the region of the HU-USP was also studied during the research period. 
Statistical analysis was performed by calculating the odds ratio of the frequencies of consultations and hospital admissions in the pre-vaccine and post-vaccine period, with a chi-squared test used to determine if there was a difference between the variables in the period studied. Similarly, the odds ratio was calculated for rotavirus positivity in the pre-vaccine and post-vaccine period, with a chi-squared test used to determine if there was a difference in the periods studied. The level of significance to accept the difference between the variables was less than 0.05 . The percentage reduction in consultations and hospital admissions was calculated using the formula below:

$$
\text { Reduction }(\%)=(1-\text { odds ratio }) \times 100
$$

The software used was SPSS 16.0.

The protocol was approved by the Research Ethics Committee on 3/4/11 (CAEE: 0106.0.198,000-10, doc 1079/10).

\section{RESULTS}

The description of the total number of emergency room consultations; the number of consultations for acute diarrhea; the consultation rate for acute diarrhea in relation to general consultations; the total number of hospital admissions; the number of hospital admissions for acute diarrhea; the hospital admission rate for acute diarrhea in relation to general admissions and the average age of the children cared for in the pre-vaccine and post-vaccine periods are described in Table 1.

To observe the seasonality of the consultations and hospital admissions due to acute diarrhea, the monthly rates of consultations due to acute diarrhea were studied in relation to the general consultations and monthly admission rates for acute diarrhea in relation to general admissions in the pre-vaccine and post-vaccine periods (Charts 1 and 2).

Comparing the number of consultations due to acute diarrhea in the post-vaccine period in relation to the pre-vaccine period we obtained an odds ratio of 0.94 (95CI 0.91 to $0.96, p<0.001)$. Therefore, there was a $6 \%$ reduction (95CI 4 to $9 \%$ ) in the rate of consultations for acute diarrhea after the introduction of the vaccine. In the hospital admission rate, the odds ratio of the post-vaccine period in relation to the pre-vaccine period is 0.6 (95CI 0.46 to $0.78, \mathrm{p}<0.001)$. Therefore, there was a $40 \%$ reduction (95CI 22 to $54 \%$ ) in the hospital admission rate for acute diarrhea after the introduction of the vaccine (Table 2).

In the months of peak rotavirus infection (May and June), the odds ratio of the rate of emergency room consultations in the post-vaccine period in relation to the pre-vaccine period is 0.6 (95CI 0.56 to $0.64, \mathrm{p}<0.001$ ). Therefore, there was a $40 \%$ reduction ( $95 \mathrm{CI} 36$ to $44 \%$ ) in the rate of consultations for acute diarrhea in the peak months after the introduction of the vaccine. As for the hospital admission rate in the peak months, the odds ratio of the post-vaccine period in relation to the pre-vaccine period is 0.18 ( $95 \mathrm{CI} 0.08$ to $0.38, \mathrm{p}<0.001$ ). Therefore, there was an $82 \%$ reduction (95CI 62 to $92 \%$ ) in the hospital admission rate for acute diarrhea in the peak months after the introduction of the vaccine (Table 3).

According to the Municipal Health Department, vaccination coverage in the region studied was $87.9 \%$ in 2007 , $91.3 \%$ in 2008 and $75.2 \%$ in 2009.

TABLE 1 Description of the total number of emergency room consultations, the number of consultations for acute diarrhea, the consultation rate for acute diarrhea in relation to general consultations, the total number of hospital admissions, the number of hospital admissions for acute diarrhea, the hospital admission rate for acute diarrhea in relation to general admissions, and the average age in the pre-vaccine and post-vaccine periods.

\begin{tabular}{|c|c|c|}
\hline & Pre-vaccine (2003-2005) & Post-vaccine (2007-2009) \\
\hline Number of emergency room consultations & 143,075 & 133,598 \\
\hline Mean age of the children cared for in the ER (in months) & 22.9 & 23.3 \\
\hline Number of consultations for acute diarrhea & 12,274 & 10,803 \\
\hline Consultation rate for acute diarrhea per 1,000 general consultations & 85.8 & 80.9 \\
\hline Mean age of consultations for acute diarrhea (in months) & 23.8 & 25.1 \\
\hline Total number of hospital admissions & 3,478 & 3,852 \\
\hline Mean age of hospitalized children (in months) & 17.6 & 18.9 \\
\hline Number of hospital admissions for acute diarrhea & 142 & 96 \\
\hline Hospital admission rate for acute diarrhea per 1,000 general admissions & 40.8 & 24.9 \\
\hline Mean age of admission for acute diarrhea (in months) & 11.3 & 15.8 \\
\hline
\end{tabular}




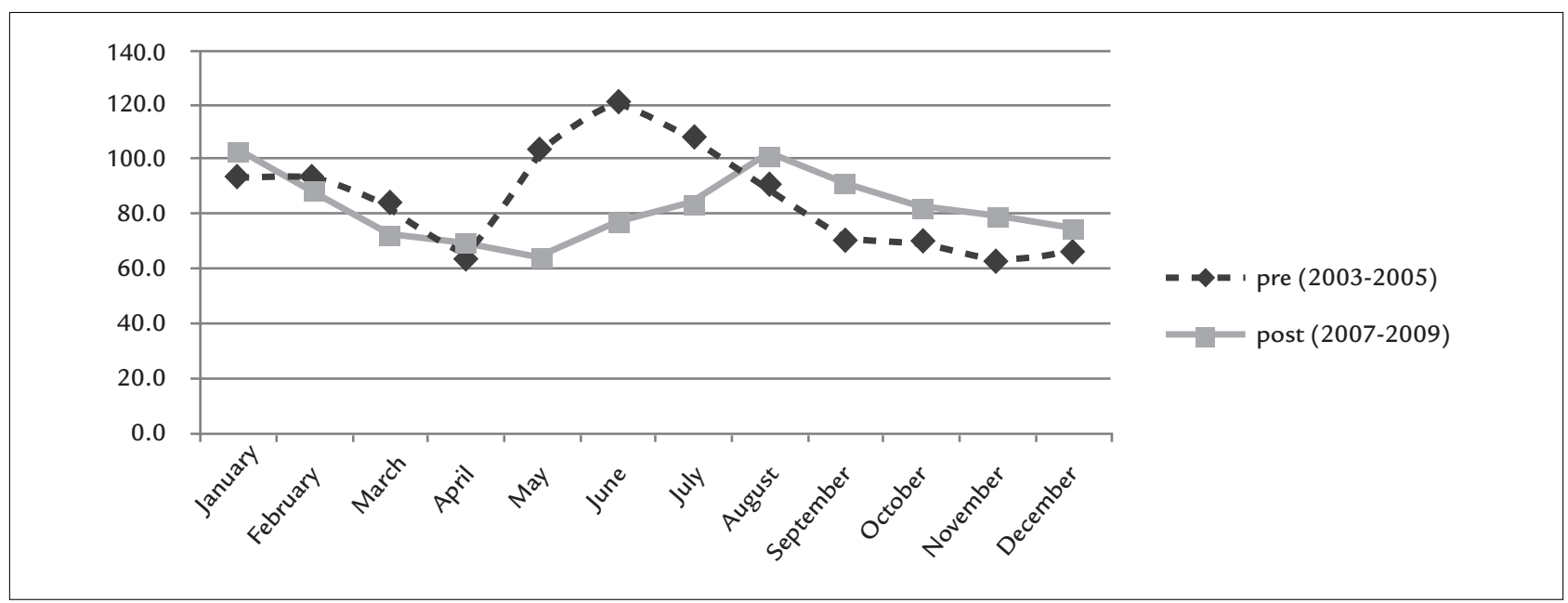

CHART 1 Monthly rate of consultations due to acute diarrhea at the emergency room per 1,000 for general consultations in the pre-vaccine period and the monthly rate of consultations due to acute diarrhea at the emergency room per 1,000 general consultations in the post-vaccine period.

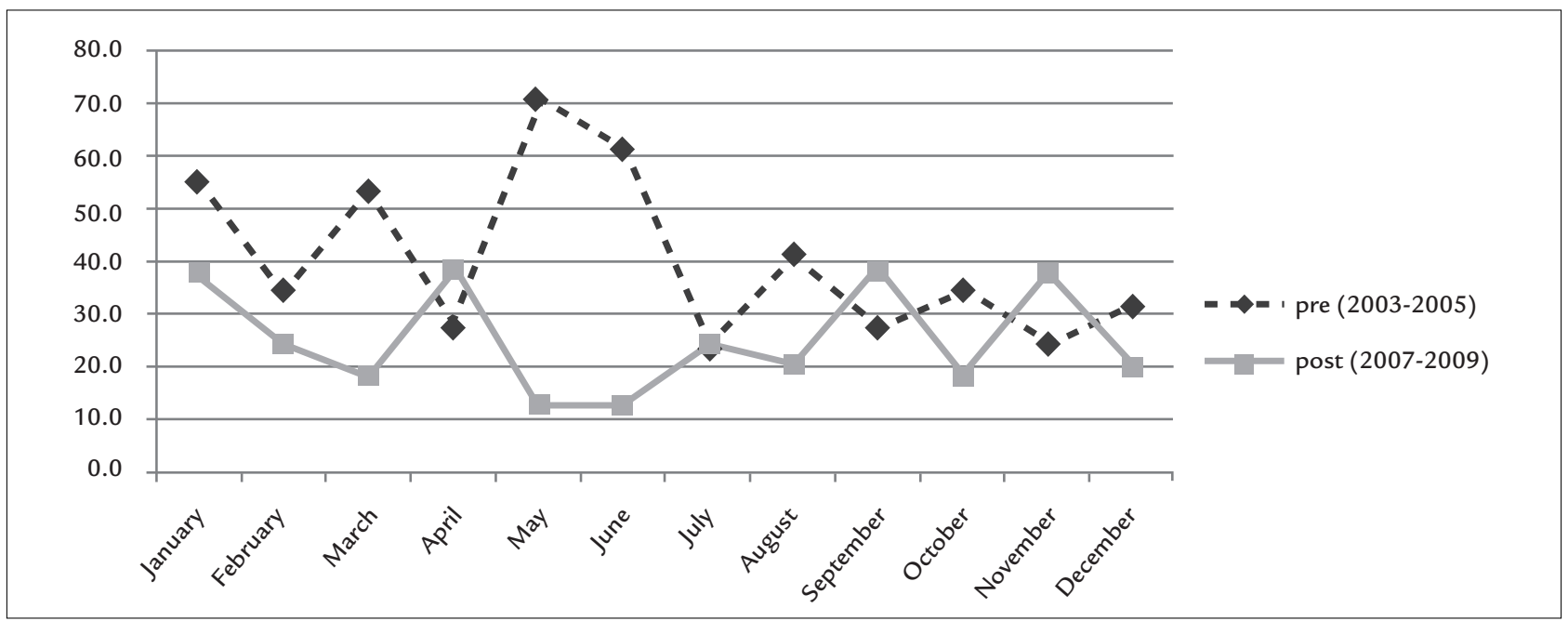

CHART 2 Monthly hospital admission rate due to acute diarrhea per 1,000 admissions in the pre-vaccine period and the monthly hospital admission rate due to acute diarrhea per 1,000 admissions in the post-vaccine period.

\section{TABLE 2 Relationship between the rate of consultations and hospital admissions for acute diarrhea (ADD) in the pre-} -vaccine and post-vaccine period.

\begin{tabular}{|c|c|c|c|c|c|c|c|c|c|c|}
\hline & \multicolumn{10}{|c|}{ Diagnosis } \\
\hline & \multirow[t]{2}{*}{ Period } & \multicolumn{2}{|l|}{ ADD } & \multicolumn{2}{|c|}{ Non-ADD } & \multirow[t]{2}{*}{ OR } & \multicolumn{2}{|l|}{$95 \mathrm{Cl}$} & \multirow[t]{2}{*}{ Total } & \multirow[t]{2}{*}{$\mathrm{P}^{*}$} \\
\hline & & $\mathbf{N}$ & $\%$ & $\mathbf{N}$ & $\%$ & & Inferior & Superior & & \\
\hline \multirow[t]{3}{*}{ Consultations } & 2003 to 2005 & 12274 & 8.6 & 130801 & 91.4 & 1.00 & & & 143075 & $<0.001$ \\
\hline & 2007 to 2009 & 10803 & 8.1 & 122795 & 91.9 & 0.94 & 0.91 & 0.96 & 133598 & \\
\hline & Total & 23077 & 8.3 & 253596 & 91.7 & & & & 276673 & \\
\hline \multirow[t]{3}{*}{ Hospital admissions } & 2003 to 2005 & 142 & 4.1 & 3336 & 95.9 & 1.00 & & & 3478 & $<0.001$ \\
\hline & 2007 to 2009 & 96 & 2.5 & 3756 & 97.5 & 0.60 & 0.46 & 0.78 & 3852 & \\
\hline & Total & 238 & 3.2 & 7092 & 96.8 & & & & 7330 & \\
\hline
\end{tabular}

*The p-value was calculated using chi-squared test. 
TABLE 3 Relationship between the rate of consultations and hospital admissions for acute diarrhea (ADD) in the peak months of rotavirus infection (May and June) in the pre-vaccine and post-vaccine periods.

\begin{tabular}{|c|c|c|c|c|c|c|c|c|c|c|}
\hline & \multirow{3}{*}{ Period } & \multicolumn{9}{|c|}{ Diagnosis } \\
\hline & & \multicolumn{2}{|l|}{ ADD } & \multicolumn{2}{|c|}{ Non-ADD } & \multirow[t]{2}{*}{ OR } & \multicolumn{2}{|l|}{$95 \mathrm{Cl}$} & \multirow[t]{2}{*}{ Total } & \multirow[t]{2}{*}{$\mathrm{P}^{*}$} \\
\hline & & $\mathbf{N}$ & $\%$ & $\mathbf{N}$ & $\%$ & & Inferior & Superior & & \\
\hline \multirow[t]{3}{*}{ Consultations } & 2003 to 2005 & 3257 & 11.2 & 25817 & 88.8 & 1.00 & & & 29074 & $<0.001$ \\
\hline & 2007 to 2009 & 1624 & 7.0 & 21431 & 93.0 & 0.60 & 0.56 & 0.64 & 23055 & \\
\hline & Total & 4881 & 9.4 & 47248 & 90.6 & & & & 52129 & \\
\hline \multirow[t]{3}{*}{ Hospital admissions } & 2003 to 2005 & 45 & 6.6 & 639 & 93.4 & 1.00 & & & 684 & $<0.001$ \\
\hline & 2007 to 2009 & 8 & 1.2 & 640 & 98.8 & 0.18 & 0.08 & 0.38 & 648 & \\
\hline & Total & 53 & 4.0 & 1279 & 96.0 & & & & 1332 & \\
\hline
\end{tabular}

*The p-value was calculated using chi-squared test.

\section{Discussion}

Analyzing the monthly rate of consultations due to acute diarrhea at the emergency room in the pre-vaccine and post-vaccine periods in the months of May and June, the decline in the rate of emergency room consultations becomes more evident. The statistical analysis showed a $6 \%$ reduction (95CI 4 to $9 \%, \mathrm{p}<0.001$ ) in the rate of emergency room consultations in the post-vaccine period compared to the pre-vaccine period, while in the months of May and June, grouped together, the reduction reached $40 \%$ (95CI 36 to $44 \%, \mathrm{p}<0.001$ ). In relation to these results, Munford et al. ${ }^{6}$ had already shown that the detection of rotavirus in the city of São Paulo is higher in May and June and, in our study, we noted the greatest reduction in the consultation rates for acute diarrhea in these months. Considering that studies conducted in Brazil on the etiology of acute diarrhea show that rotavirus is responsible by 11.9 to $20.8 \%$ of visits to the emergency room due acute diarrhea, ${ }^{7-9}$ the reduction found in the present study was lower (6\%). In a study in Australia, Davey et al. found an $18.3 \%$ reduction in emergency room consultations. ${ }^{14}$

The efficacy of the vaccine for severe acute diarrhea due to rotavirus was $84.7 \%$ in a study of eleven countries in Latin America and Finland, ${ }^{10}$ and $83.8 \%$ for acute diarrhea due to rotavirus (all severities) in Europe. ${ }^{15}$ Meanwhile, the efficacy in Brazil (in the city of Belém, Pará) was $63.5 \% .{ }^{16}$ The efficacy of the vaccine in the USA regarding emergency room consultations due to diarrhea caused by rotavirus was $78 \%{ }^{17}$ In Brazil, a study in Belém, Pará, ${ }^{18}$ showed that the effectiveness of the vaccine against hospital admissions due to diarrhea caused by rotavirus in mild and moderate cases (depending on the chosen control group) varied between 25.6 and $72.7 \%$, and a study in Aracaju ${ }^{19}$ showed that the effectiveness of the vaccine against acute diarrhea caused by rotavirus in emergency room patients (all severities) was at least $79 \%$.
Taking into account the vaccination coverage in the period of study (75.2 to $91.3 \%$ ), and the lower effectiveness of the vaccine for mild and moderate cases, we can conclude that the value found for the reduction in emergency room consultations rates for acute diarrhea is as expected.

It is estimated that around $40 \%$ of hospital admissions due to acute diarrhea in Brazil are caused by rotavirus infection, ${ }^{5}$ and this was exactly the value found in our study for the reduction in hospital admissions due to acute diarrhea after the introduction of the vaccine. Impact studies conducted in Brazil using data from the $\mathrm{Da}$ tasus have shown a reduction of hospital admissions due to acute diarrhea in children less than 5 years of age. In Brazil, the reduction ranged from 17 to $21.4 \% ;^{12,20}$ in the South and Southeast region, the reduction was $35 \%$ in the year $2007 ;{ }^{21}$ in the Southeast region the reduction was $21 \%{ }^{12}$ and in the State of São Paulo the reduction ranged from 21 to $40 \%{ }^{13,22}$

In the peak period of rotavirus infection (May and June), the reduction in hospital admissions due to acute diarrhea after the introduction of the vaccine was $82 \%$, suggesting that the effectiveness of the vaccine was good. This result is compatible with efficacy studies conducted in Europe and Latin America, where the efficacy of the vaccine against hospital admissions ranged from 85 to 96\% ${ }^{11,15}$ An efficacy study of the vaccine against hospital admission conducted in Belém, Pará, showed a value of $81.2 \%{ }^{16}$ However, studies in Africa and Asia showed lower efficacy, ranging from 39.3 to $57.5 \%$. $^{23-25}$

In Brazil, studies of the effectiveness of the vaccine against hospital admissions have shown very different values. The study by Justino et al., ${ }^{18}$ conducted in Belém, Pará, showed effectiveness between 40 and $75.8 \%$, depending on the chosen control group, and the study by Ichihara et al. ${ }^{26}$ conducted in five Brazilian regions, showed effectiveness of $76 \%$. 
In the city of São Paulo, Sáfadi et al. ${ }^{13}$ showed a $69.2 \%$ decrease in the positivity of rotavirus investigations in the stools of patients under the age of 1 year admitted to a private hospital after the introduction of rotavirus immunization.

Considering the result of our study, together with earlier studies, we can infer that the monovalent vaccine for rotavirus shows good effectiveness against hospital admission for acute diarrhea in the city of São Paulo.

The present study has limitations, as it is a retrospective ecological study comparing populations for similar periods but at different times. Therefore, factors such as the improvement of basic sanitation and health system may have affected the results. It was not possible to find out the vaccination status of the children who participated in the study, and information on the vaccination status had to be inferred through data kept by the Municipal Health Department.

\section{Conclusion}

Comparing the pre-vaccine period (2003 to 2005) with the post-vaccine period (2007 to 2009) in children under 5 years of age cared for at the University of São Paulo's University Hospital, we noted a:

- $6 \%$ reduction in consultations due to acute diarrhea in the emergency room;

- $40 \%$ reduction in hospital admissions due to acute diarrhea;

- $40 \%$ reduction in emergency room consultations and $82 \%$ reduction in hospital admissions due acute diarrhea in the months of May and June (the peak rotavirus infection period).

\section{Resumo}

Impacto da vacinação contra rotavírus nas consultas de pronto-socorro e internações por doença diarreica aguda em crianças menores de 5 anos de idade

Introdução: a doença diarreica aguda é a segunda causa de morte em crianças abaixo de 5 anos de idade. No Brasil, entre 2003 e 2009, a diarreia aguda foi responsável por cerca de 100 mil internações por ano e por $4 \%$ das mortes em crianças abaixo de 5 anos de idade. O rotavírus é a principal etiologia de diarreia aguda grave. A vacina monovalente (RV1) contra o rotavírus foi introduzida em 2006.

Objetivos: verificar o impacto da vacina monovalente contra rotavírus nas consultas de pronto-socorro e inter- nações por doença diarreica aguda em crianças menores de 5 anos de idade.

Método: foi realizado um estudo ecológico retrospectivo no Hospital Universitário da Universidade de São Paulo. O período foi dividido em pré-vacina (2003 a 2005) e pós-vacina (2007 a 2009). Foram incluídas todas as crianças abaixo de 5 anos que passaram em consulta no pronto-socorro. Foram obtidas as taxas de consultas no pronto-socorro e internações por doença diarreica aguda. A redução nas taxas foi obtida através da fórmula: redução $(\%)=(1-$ odds ratio $) \times 100$.

Resultados: no período pré-vacina, a taxa de consultas por diarreia aguda foi de 85,8 consultas por 1.000 consultas gerais, enquanto no período pós-vacina a taxa de consultas por diarreia aguda foi 80,9 por 1.000, uma redução de $6 \%$ (IC95\% 4-9, p<0,001). A taxa de internação por diarreia aguda era 40,8 internações por 1.000 e caiu para 24,9 por 1.000 , redução de $40 \%$ (IC95\% 22-54, p<0,001).

Conclusão: após a introdução da vacina contra rotavírus houve uma redução de $6 \%$ nas consultas por diarreia aguda no pronto-socorro e de $40 \%$ nas internações por diarreia aguda.

Palavras-chave: diarreia, rotavírus, vacinas, serviços médicos de emergência, hospitalização, epidemiologia, pré-escolar.

\section{References}

1. World Health Organization. WHO Media Centre. Diarrhoeal disease. Fact sheet no. 330. April 2013 [cited 2014 May 07]. Available from: http://www. who.int/mediacentre/factsheets/fs330/en/.

2. World Health Organization. World Health Statistics 2013. Geneva; 2013 [cited 2014 May 07]. Available from: http://www.who.int/gho/publications/ world_health_statistics/EN_WHS2013_Full.pdf?ua=1.

3. Brasil. Ministério da Saúde. DATASUS. Departamento de Informática do SUS. Informações de saúde (TABNET) [cited 2010 Aug 03]. Available from: http://datasus.saude.gov.br/.

4. Parashar UD, Burton A, Lanata C, Boschi-Pinto C, Shibuya K, Steele D, et al. Global mortality associated with rotavirus disease among children in 2004. J Infect Dis. 2009; 200(Suppl 1):S9-15.

5. Ramani S, Kang G. Viruses causing childhood diarrhoea in the developing world. Curr Opin Infect Dis. 2009; 22(5):477-82.

6. Munford V, Gilio AE, de Souza EC, Cardoso DM, Cardoso D, Borges AM, et al. Rotavirus gastroenteritis in children in 4 regions in Brazil: a hospitalbased surveillance study. J Infect Dis. 2009; 200(Suppl 1):S106-13.

7. da Rosa e Silva ML, Naveca FG, Pires de Carvalho I. Epidemiological aspects of rotavirus infections in Minas Gerais, Brazil. Braz J Infect Dis. 2001; 5(4):215-22.

8. Gomes TA, Rassi V, MacDonald KL, Ramos SR, Trabulsi LR, Vieira MA, et al. Enteropathogens associated with acute diarrheal disease in urban infants in São Paulo, Brazil. J Infect Dis. 1991; 164(2):331-7.

9. Souza EC, Martinez MB, Taddei CR, Mukai L, Gilio AE, Racz ML, et al. [Etiologic profile of acute diarrhea in children in São Paulo]. J Pediatr (Rio J). 2002; 78(1):31-8.

10. Ruiz-Palacios GM, Pérez-Schael I, Velázquez FR, Abate H, Breuer T, Clemens SC, et al.; Human Rotavirus Vaccine Study Group. Safety and efficacy of an attenuated vaccine against severe rotavirus gastroenteritis. N Engl J Med. 2006; 354(1):11-22. 
11. do Carmo GM, Yen C, Cortes J, Siqueira AA, de Oliveira WK, Cortez-Escalante $\mathrm{JJ}$, et al. Decline in diarrhea mortality and admissions after routine childhood rotavirus immunization in Brazil: a time-series analysis. PLoS Med. 2011; 8(4):e1001024.

12. Fernandes EG, Sato HK, Leshem E, Flannery B, Konstantyner TC, Veras MA, et al. Impact of rotavirus vaccination on diarrhea-related hospitalizations in São Paulo State, Brazil. Vaccine. 2014; 32(27):3402-8.

13. Sáfadi MA, Berezin EN, Munford V, Almeida FJ, de Moraes JC, Pinheiro CF, et al. Hospital-based surveillance to evaluate the impact of rotavirus vaccination in São Paulo, Brazil. Pediatr Infect Dis J. 2010; 29(11):1019-22.

14. Davey HM, Muscatello DJ, Wood JG, Snelling TL, Ferson MJ, Macartney KK. Impact of high coverage of monovalent human rotavirus vaccine on Emergency Department presentations for rotavirus gastroenteritis. Vaccine. 2015; 33(14):1726-30

15. Vesikari T, Karvonen A, Prymula R, Schuster V, Tejedor JC, Cohen R, et al. Efficacy of human rotavirus vaccine against rotavirus gastroenteritis during the first 2 years of life in European infants: randomised, double-blind controlled study. Lancet. 2007; 370 (9601):1757-63.

16. Araujo EC, Clemens SA, Oliveira CS, Justino MC, Rubio P, Gabbay YB, et al. Safety, immunogenicity, and protective efficacy of two doses of RIX4414 live attenuated human rotavirus vaccine in healthy infants. J Pediatr (Rio J). 2007; 83(3):217-24.

17. Payne DC, Boom JA, Staat MA, Edwards KM, Szilagyi PG, Klein EJ, et al. Effectiveness of pentavalent and monovalent rotavirus vaccines in concurrent use among US children < 5 years of age, 2009-2011. Clin Infect Dis. 2013; 57(1):13-20.

18. Justino MC, Linhares AC, Lanzieri TM, Miranda Y, Mascarenhas JD, Abreu $\mathrm{E}$, et al. Effectiveness of the monovalent G1P[8] human rotavirus vaccine against hospitalization for severe G2P [4] rotavirus gastroenteritis in Belém, Brazil. Pediatr Infect Dis J. 2011; 30(5):396-401.
19. Gurgel RG, Bohland AK, Vieira SC, Oliveira DM, Fontes PB, Barros VF, et al. Incidence of rotavirus and all-cause diarrhea in northeast Brazil following the introduction of a national vaccination program. Gastroenterology. 2009; 137(6):1970-5.

20. Gurgel RQ, Ilozue C, Correia JB, Centenari C, Oliveira SM, Cuevas LE. Impact of rotavirus vaccination on diarrhoea mortality and hospital admissions in Brazil. Trop Med Int Health. 2011; 16(9):1180-4.

21. Lanzieri TM, Costa I, Shafi FA, Cunha MH, Ortega-Barria E, Linhares AC, et al. Trends in hospitalizations from all-cause gastroenteritis in children younger than 5 years of age in Brazil before and after human rotavirus vaccine introduction, 1998-2007. Pediatr Infect Dis J. 2010; 29(7):673-5.

22. Teles E, Moscovici L, Monteiro RA, Alves D, Laprega MR, Bellissimo-Rodrigues F. The effectiveness of a rotavirus vaccine in preventing hospitalizations and deaths presumably due to acute infectious diarrhea in Brazilian children: a quasi-experimental study. Rev Soc Bras Med Trop. 2015; 48(2):129-35.

23. Madhi SA, Cunliffe NA, Steele D, Witte D, Kirsten M, Louw C, et al. Effect of human rotavirus vaccine on severe diarrhea in African infants. $\mathrm{N}$ Engl J Med. 2010; 362(4):289-98.

24. Armah GE, Sow SO, Breiman RF, Dallas MJ, Tapia MD, Feikin DR, et al. Efficacy of pentavalent rotavirus vaccine against severe rotavirus gastroenteritis in infants in developing countries in sub-Saharan Africa: a randomised, doubleblind, placebo-controlled trial. Lancet. 2010; 376(9741):606-14.

25. Zaman K, Dang DA, Victor JC, Shin S, Yunus M, Dallas MJ, et al. Efficacy of pentavalent rotavirus vaccine against severe rotavirus gastroenteritis in infants in developing countries in Asia: a randomised, double-blind, placebocontrolled trial. Lancet. 2010; 376(9741):615-23.

26. Ichihara MY, Rodrigues LC, Teles Santos CA, Teixeira MaG, De Jesus SR, Alvim De Matos SM, et al. Effectiveness of rotavirus vaccine against hospitalized rotavirus diarrhea: A case-control study. Vaccine. 2014; 32(23):2740-7 